\title{
An Axiomatization of the Proportional Rule in Financial Networks
}

Citation for published version (APA):

Csóka, P., \& Herings, P. J-J. (2021). An Axiomatization of the Proportional Rule in Financial Networks. Management Science, 67(5), 2799-2812. https://doi.org/10.1287/mnsc.2020.3700

Document status and date:

Published: 01/05/2021

DOI:

$10.1287 / \mathrm{mnsc} .2020 .3700$

Document Version:

Publisher's PDF, also known as Version of record

Document license:

Taverne

Please check the document version of this publication:

- A submitted manuscript is the version of the article upon submission and before peer-review. There can be important differences between the submitted version and the official published version of record.

People interested in the research are advised to contact the author for the final version of the publication, or visit the DOI to the publisher's website.

- The final author version and the galley proof are versions of the publication after peer review.

- The final published version features the final layout of the paper including the volume, issue and page numbers.

Link to publication

\footnotetext{
General rights rights.

- You may freely distribute the URL identifying the publication in the public portal. please follow below link for the End User Agreement:

www.umlib.nl/taverne-license

Take down policy

If you believe that this document breaches copyright please contact us at:

repository@maastrichtuniversity.nl

providing details and we will investigate your claim.
}

Copyright and moral rights for the publications made accessible in the public portal are retained by the authors and/or other copyright owners and it is a condition of accessing publications that users recognise and abide by the legal requirements associated with these

- Users may download and print one copy of any publication from the public portal for the purpose of private study or research.

- You may not further distribute the material or use it for any profit-making activity or commercial gain

If the publication is distributed under the terms of Article $25 \mathrm{fa}$ of the Dutch Copyright Act, indicated by the "Taverne" license above, 


\title{
An Axiomatization of the Proportional Rule in Financial Networks
}

\author{
Péter Csóka, ${ }^{a, b}$ P. Jean-Jacques Herings ${ }^{c}$ \\ ${ }^{\mathbf{a}}$ Department of Finance, Corvinus University of Budapest, 1093 Budapest, Hungary; ${ }^{\mathbf{b}}$ Momentum Game Theory Research Group, Centre for \\ Economic and Regional Studies, Hungarian Academy of Sciences Centre of Excellence, 1097 Budapest, Hungary; ${ }^{\mathbf{c}}$ Department of Economics, \\ Maastricht University, 6200 MD Maastricht, Netherlands \\ Contact: peter.csoka@uni-corvinus.hu, (D) https://orcid.org/0000-0003-1703-5835 (PC); P.Herings@maastrichtuniversity.nl, \\ (iD) https://orcid.org/0000-0002-1100-8601 (PJ-JH)
}

Received: May 17, 2019

Revised: January 13, 2020; April 9, 2020

Accepted: April 29, 2020

Published Online in Articles in Advance: October 5, 2020

JEL Classification: C71, G10.

https://doi.org/10.1287/mnsc.2020.3700

Copyright: ๑) 2020 INFORMS

\begin{abstract}
The most important rule to determine payments in real-life bankruptcy problems is the proportional rule. Many such bankruptcy problems are characterized by network aspects, and the values of the agents' assets are endogenous as they depend on the extent to which claims on other agents can be collected. These network aspects make an axiomatic analysis challenging. This paper is the first to provide an axiomatization of the proportional rule in financial networks. Our main axiom is invariance to mitosis. The other axioms are claims boundedness, limited liability, priority of creditors, continuity, and impartiality.
\end{abstract}

History: Accepted by Manel Baucells, decision analysis.

Funding: P. Csóka received financial support from the János Bolyai scholarship of the Hungarian Academy of Sciences; COST Action IC1205 on Computational Social Choice; and the National Research, Development, and Innovation Office (Hungary) [Grant K-120035].

Keywords: financial networks $\cdot$ systemic risk $\cdot$ bankruptcy rules $\cdot$ proportional rule

\section{Introduction}

The principle of proportionality plays an important role in bankruptcy law across the globe. The European Commission (EC) Council Regulation on insolvency proceedings states that ${ }^{1}$

Every creditor should be able to keep what he has received in the course of insolvency proceedings but should be entitled only to participate in the distribution of total assets in other proceedings if creditors with the same standing have obtained the same proportion of their claims.

The principle of proportionality is also important for American bankruptcy law, according to which claimants of equal status should receive payments proportional to the value of their liabilities; see Kaminski (2000).

Given the prominence of the proportional rule in practice, it is important to understand its crucial features by finding an axiomatization. Starting with the seminal paper of $\mathrm{O}^{\prime}$ Neill (1982), the literature that takes an axiomatic approach to the bankruptcy problem assumes there is a single bankrupt agent, while the other agents have claims on its estate. We refer to this class of problems as claims problems. The central question is how this estate should be divided over the claims, and the axiomatic approach has provided firm underpinnings for a number of well-known division rules. See Thomson (2013) and Thomson (2015) for an overview of this stream of the literature.
Notable axiomatizations of the proportional rule for claims problems are given by Young (1988), Angeles de Frutos (1999), Moreno-Ternero (2006), and Ju et al. (2007). The main axioms used by these papers are selfduality, composition up, composition down, nonmanipulability, and merging- and splitting-proofness. For related axiomatizations, see Tasnádi (2002) on probabilistic rationing methods and Moulin (2016) on proportional assignment and rationing of goods with different characteristics.

Recent crisis on financial markets related to the Lehman bankruptcy as well as sovereign debt problems of European countries have spurred an extensive literature on systemic risk that takes a network perspective to the bankruptcy problem, starting with the contribution by Eisenberg and Noe (2001). The literature that is based on this model, either extending it (Cifuentes et al. 2005, Shin 2008, Rogers and Veraart 2013, Schuldenzucker et al. 2020) or using it to relate the number and magnitude of defaults to the network topology (Gai and Kapadia 2010, Elliott et al. 2014, Acemoglu et al. 2015, Glasserman and Young 2015, Capponi et al. 2016) or measuring systemic risk (Chen et al. 2013, Demange, 2018), uses the proportional rule to determine the mutual payments by the agents. For an overview of this stream of the literature, we refer to the excellent survey by Glasserman and Young (2016).

The aim of this paper is to provide axiomatic foundations for the use of the proportional rule for 
bankruptcy problems in financial networks defined by Eisenberg and Noe (2001). A financial network consists of a set of agents, with each agent being characterized by its endowments and its liabilities toward the other agents. A bankruptcy rule determines the actual payments of agents to each other, collected in a payment matrix. More technically, a bankruptcy rule is simply a function that assigns to each financial network a payment matrix. To clearly distinguish concepts, we use the terminology bankruptcy rule for financial network problems and division rule for the simpler context of claims problems with a single bankrupt agent.

An agent is in fundamental default if it cannot fully pay its liabilities, even if it receives full payments on all its claims on the other agents. In a network setting, a default can also result from contagion, where an agent defaults only because other agents are not fully paying their liabilities. Because of these mutual dependencies, it is not trivial to define the proportional rule in a financial network. We follow the seminal contribution by Eisenberg and Noe (2001) and proceed as follows. First, one determines the asset value of an agent, the value of its endowments together with the payments as collected from the other agents. Under the proportional rule, an agent spends its asset value in a proportional way over its liabilities, up to the value of those liabilities. Subtracting the payments as made by an agent from its asset value yields an agent's equity. Because of the mutual dependencies caused by the network aspect, one has to solve a system of equations to determine the actual payments. Under the proportional rule, the agents' asset values and equities are therefore determined endogenously in a financial network.

Agents in financial networks may engage in spinoffs and mergers. When such activities do not generate added value, they should not influence the payments made to and received from agents not involved in them. The axiom that requires that the split of an agent into multiple agents or the merger of a set of agents should not affect the payment matrix is called nonmanipulability in the literature. The proportional rule does not satisfy nonmanipulability. As an example, one expects the merger of a bankrupt and a solvent agent to affect the payment matrix generated by the proportional rule, because part of the assets of the solvent agent that were not seized before can now be used for making payments related to claims on the bankrupt agent. The other way around, if an agent is allowed to create a new entity that receives all its liabilities, but none of its claims or endowments, then the agent is clearly going to benefit because it will end up in paying none of its liabilities. This kind of manipulation is illegal in reality, because in winding up or in insolvency proceedings, the borrower is not allowed to do anything that would threaten directly or indirectly the payments to its lenders. We show that nonmanipulability is incompatible with any reasonable bankruptcy rule in financial networks.

We, therefore, want to restrict spin-offs and mergers in financial networks to situations that are balanced in the way endowments and claims are reshuffled. A spin-off that receives liabilities should receive a corresponding amount of endowments and claims. The simplest way to achieve this is to restrict attention to manipulations involving identical agents. ${ }^{2}$ Agents are identical if they have the same endowments, claims, and liabilities, which implies, for instance, that mutual liabilities between them are equal to zero. The axiom called invariance to mitosis requires that the split of an agent into multiple identical agents or the merger of a group of agents that are identical should not affect the payment matrix. This is clearly a very weak axiom.

We show that invariance to mitosis together with claims boundedness, limited liability, priority of creditors, continuity, and impartiality axiomatize the proportional rule in financial networks. Claims boundedness expresses that no agent pays an amount in excess of its liabilities. A bankruptcy rule satisfies limited liability if it leads to a payment matrix, such that none of the agents ends up with negative equity. Priority of creditors is satisfied if the only circumstance under which an agent is allowed to default is when its equity is equal to zero. Continuity implies that small changes in the financial network imply small changes in the resulting payment matrix. Impartiality requires that two agents with the same claim on a third agent should receive the same payment from it. We show that the axioms are independent. Although the very weak requirement of invariance to mitosis is sufficient to pin down the proportional rule, the proportional rule can be shown to satisfy nonmanipulability for a much wider range of situations. It holds whenever all agents involved in a split remain solvent, which corresponds exactly to those cases that are legally allowed.

The way Eisenberg and Noe (2001) extend the proportional rule for claims problems to the set-up of financial networks can be used to extend any division rule for claims problems to the set-up of financial networks. The resulting bankruptcy rule for financial networks consists of computing each agent's asset value and then making payments in accordance with the given division rule for claims problems. Such a bankruptcy rule is called a division rule-based bankruptcy rule. Groote Schaarsberg et al. (2018) extend the Aumann-Maschler division rule for claims problems to a bankruptcy rule for financial networks. Different from the approach in this paper, they consider the resulting equity rather than the entire payment matrix. They restrict attention to the class of division- 
rule-based bankruptcy rules and provide an axiomatization for the equity resulting from the bankruptcy rule based on the Aumann-Maschler division rule.

Not all bankruptcy rules are based on division rules. For instance, a bankruptcy rule that consists of pairwise netting all mutual claims first and next applying the proportional rule to the resulting liabilities is not in this class, because in this case, payments do not only depend on the asset value of an agent and its liabilities, but also on its claims toward other agents. Our axiomatization of the proportional rule does not impose any a priori structure on bankruptcy rules. Absence of pairwise netting, for instance, is therefore a consequence of our axioms rather than an assumption.

Finally, we would like to mention an emerging literature on the extension of the bankruptcy literature to network problems as appearing in operations research. Bjørndal and Jörnsten (2010) analyze generalized bankruptcy problems with multiple estates as flow-sharing problems and define the nucleolus and the constrained egalitarian solution for such problems. Moulin and Sethuraman (2013) consider bipartite rationing problems, where agents can have claims on a subset of unrelated estates. They consider whether rules for single resource problems can be consistently extended to their framework.

\section{Financial Networks and the Proportional Rule}

Let $\mathbb{N}$ be the set of all potential agents and $\mathcal{N}$ the collection of nonempty, finite subsets of $\mathbb{N}$.

A financial network is a triple $(N, z, L)$ with the following interpretation.

The set of agents in the financial network is given by $N \in \mathcal{N}$. The vector $z \in \mathbb{R}_{++}^{N}$ represents the endowments of the agents, which are strictly positive real numbers. The endowment of an agent includes all its tangible and intangible assets, but excludes the claims and liabilities that the agent has toward the other agents. The nonnegative liability matrix $L \in \mathbb{R}_{+}^{N \times N}$ describes the mutual claims of the agents. Its entry $L_{i j}$ is the liability of agent $i$ toward agent $j$ or, equivalently, the claim of agent $j$ on agent $i$. We make the normalizing assumption that $L_{i i}=0$. In general, it can occur that agent $i$ has a liability toward agent $j$ and vice versa, so it may happen that simultaneously $L_{i j}>0$ and $L_{j i}>0$.

Let $\Pi \in \mathbb{R}_{+}^{N \times N}$ denote the nonnegative relative liability matrix, where for $i, j \in N$,

$$
\Pi_{i j}= \begin{cases}0, & \text { if } L_{i j}=0, \\ \frac{L_{i j}}{\sum_{k \in N} L_{i k}}, & \text { otherwise. }\end{cases}
$$

The set of all matrices in $\mathbb{R}_{+}^{N \times N}$ with a zero diagonal is denoted by $M(N)$. The union over all finite sets of agents of these matrices is denoted by $\mathcal{M}=\cup_{N \in \mathcal{N}} \mathcal{M}(N)$. The partial order $\leq$ on $M(N)$ is defined in the usual way: For $P, P^{\prime} \in M(N)$, it holds that $P \leq P^{\prime}$ if and only if $P_{i j} \leq P_{i j}^{\prime}$ for all $(i, j) \in N \times N$. For $P \in M(N)$ and $i \in N$, let $P_{i} \in \mathbb{R}^{N}$ denote row $i$ of $P$. For $P_{i}, P_{i}^{\prime} \in \mathbb{R}^{N}$, we write $P_{i}<$ $P_{i}^{\prime}$ if $P_{i j} \leq P_{i j}^{\prime}$ for all $j \in N$, and there is $k \in N$ such that $P_{i k}<P_{i k}^{\prime}$. Column $i \in N$ of the matrix $P$ is denoted by $P^{i}$.

The set of all financial networks is denoted by $\mathscr{F}$.

Consider a financial network $(N, z, L) \in \mathscr{F}$. A payment matrix $P \in M(N)$ describes the mutual payments to be made by the agents - that is, $P_{i j}$ is the monetary amount to be paid by agent $i \in N$ to agent $j \in N$. Given a payment matrix $P \in M(N)$, the asset value $a_{i}(N, z, P)$ of agent $i \in N$ is given by

$$
a_{i}(N, z, P)=z_{i}+\sum_{j \in N} P_{j i}
$$

Subtracting the payments as made by an agent from its asset value yields an agent's equity. The equity $e_{i}(N, z, P)$ of an agent $i \in N$ is given by

$$
e_{i}(N, z, P)=a_{i}(N, z, P)-\sum_{j \in N} P_{i j}=z_{i}+\sum_{j \in N}\left(P_{j i}-P_{i j}\right) .
$$

It follows immediately from the above expression that the sum over agents of their equities is the same as the sum over agents of their initial endowments.

A bankruptcy rule $b$ associates to each financial network $(N, z, L) \in \mathscr{F}$ a payment matrix $P \in M(N)$. More formally, we have the following definition.

Definition 2.1. A bankruptcy rule is a function $b: \mathscr{F} \rightarrow \mathcal{M}$ such that for every $(N, z, L) \in \mathscr{F}$, it holds that $b(N, z, L) \in M(N)$.

The proportional rule $p: \mathscr{F} \rightarrow M$ is the bankruptcy rule where every agent proportionally spends its asset value over its liabilities.

Definition 2.2. The proportional rule is the function $p$ : $\mathscr{F} \rightarrow M$ such that for every $(N, z, L) \in \mathscr{F}$, it holds that $p(N, z, L)=P$, where the matrix $P$ solves the following system of equations:

$$
P_{i j}=\min \left\{\Pi_{i j}\left(z_{i}+\sum_{k \in N} P_{k i}\right), L_{i j}\right\}, \quad i, j \in N .
$$

It follows from theorem 2 in Eisenberg and Noe (2001) that the system of equations (2.1) has a unique solution. Lemma 4 in Eisenberg and Noe (2001) establishes that the payment matrix generated by the proportional rule can also be found as the solution to a 
linear programming problem. Let $(N, z, L) \in \mathscr{F}_{\mathscr{F}}$ be a financial network, and let the matrix $P^{*}$ solve the following linear programming problem, where $\mathbb{1}$ denotes a vector of ones in $\mathbb{R}^{N}$ :

$$
\begin{aligned}
& \max _{P \in \mathbb{R}_{+}^{N \times N}, \lambda \in \mathbb{R}_{+}^{N}} \sum_{i \in N} \sum_{j \in N} P_{i j,} \\
& \text { subject to } \\
& P_{i j}=\lambda_{i} L_{i j}, \quad i, j \in N, \\
& \lambda_{i} \leq 1, \quad i \in N, \\
& z+P^{\top} \mathbb{1}-P \mathbb{1} \geq 0 .
\end{aligned}
$$

Then, it holds that $p(N, z, L)=P^{*}$. The first and second constraint in the linear program (2.2) guarantee that payments are proportional to the liabilities and that no agent receives more than its claim. The third constraint ensures that no agent ends up with negative equity. The fact that $P^{*}$ maximizes the objective function implies that no agent is allowed to default when having positive equity. Otherwise, it would be possible to increase the value of the objective function by having the defaulting agent make additional payments.

In Example 2.3, we illustrate financial networks and the proportional rule in a numerical example, whereas in Example 2.4, we explain how the model has been used to assess the systemic financial stability of the Austrian banking system.

Example 2.3 (The Proportional Rule in a Numerical Example). Consider the financial network $(N, z, L) \in$ $\mathscr{F}_{F}$ with three agents $N=\{1,2,3\}$ and endowments and liabilities as in the first two blocks of Table 1. Moreover, Table 1 presents the payment matrix $P$ resulting from the proportional rule $p$ and the induced asset values and equities.

Notice that agent 2 is in fundamental default, because its endowment of 19 cannot fully pay its liabilities of 20 and 60 to agents 1 and 3, respectively, even if agent 2 receives the payment of 10 from agent 3 . However, the default of agent 3 results from contagion. In the absence of default by agent 2 , agent 3 would have an asset value equal to 84 , which is more than sufficient to pay the total value of 50 of all its liabilities. Under the proportional rule, agent 2 pays

\begin{tabular}{|c|c|c|c|c|c|c|c|c|}
\hline$z$ & \multicolumn{3}{|c|}{$L$} & \multicolumn{3}{|c|}{$P$} & $a(N, z, P)$ & $e(N, z, P)$ \\
\hline 9 & 0 & 0 & 0 & 0 & 0 & 0 & 52 & 52 \\
\hline 19 & 20 & 0 & 60 & 7 & 0 & 21 & 28 & 0 \\
\hline 24 & 40 & 10 & 0 & 36 & 9 & 0 & 45 & 0 \\
\hline 52 & & & & & & & & 52 \\
\hline
\end{tabular}
$35 \%$ and agent 3 pays $90 \%$ of its liabilities.

Table 1. The Endowments, the Liabilities, the Payment Matrix, the Asset Values, and the Equities Resulting from the Proportional Rule $p$ in Example 2.3
Example 2.4 (An Application to the Austrian Banking System). Elsinger et al. (2006) use a financial network $(N, z, L)$ to assess the systemic financial stability of the Austrian banking system. The set $N$ consists of 881 Austrian banks that report monthly to the Austrian Central Bank. The endowment $z_{i}$ of bank $i \in N$ is given by the portfolio holdings of bank $i$-that is, the value of its loans, bonds, and stocks minus its liabilities to nonbanks-and is netted by its interbank positions. For $j \in N$, the number $L_{i j}$ is given by the exposures of bank $i$ toward bank $j$ - that is, the total nominal liabilities of bank $i$ against bank $j$. The values of $z$ and $L$ are determined for September 2002 on the basis of the monthly reports to the Austrian Central Bank and the Austrian Central Bank major loans register. Total endowments $\sum_{i \in N} z_{i}$ of the banks equal 575 billion euros, and total interbank liabilities $\sum_{i \in N} \sum_{j \in N} L_{i j}$ amount to 161 billion euros.

To use the model for risk analysis, it is extended to a framework with uncertainty by assuming that future endowments are determined by the realization of a random variable $\widetilde{z}$. To determine the distribution of $\widetilde{z}$, separate estimates are made of both market risk and credit risk to which the banks are exposed, where a 10day horizon is taken for market risk and a threemonth horizon for credit risk. Each realization $z^{\prime}$ of $\widetilde{z}$, called a scenario in Elsinger et al. (2006), leads to a financial network $\left(N, z^{\prime}, L\right)$. Scenarios are analyzed both from a short-run and a long-run perspective. The short-run perspective assumes that there are no interbank payments following a bank's default in the financial network $\left(N, z^{\prime}, L\right)$. The long-run perspective uses the proportional rule to determine the payment matrix and to calculate the number of banks subject to fundamental and contagion default.

As discussed in Example 2.4, the use of the proportional rule implicitly takes a long-run perspective by assuming that the entire endowments of a defaulting bank can be used to make payments to its creditors. This assumption is less restrictive than it may seem at first sight, as it follows from the analysis in Csóka and Herings (2018) that the final payment matrix is not sensitive to the exact timing of the payments. It is therefore not needed that the liquidation of a bankrupt bank takes place immediately, and the model is consistent with the case where the unwinding of a defaulting bank's assets can take a substantial amount of time.

Upper (2011) presents a survey of 15 applied studies that use the Eisenberg and Noe (2001) framework to assess the frequency and severity of contagion in interbank markets for a number of countries. This survey puts particular emphasis on the way the matrix $L$ can be estimated on the basis of, often limited, available data. 


\section{Basic Axioms}

In this section, we define and discuss five basic axioms for bankruptcy rules $b: \mathscr{F} \rightarrow M$.

Axiom 3.1 (Claims Boundedness). For every $F \in \mathscr{F}$, it holds that $b(F) \leq L$.

Axiom 3.2 (Limited Liability). For every $F \in \mathscr{F}$, for every $i \in$ $N$, it holds that $e_{i}(N, z, b(F)) \geq 0$.

Axiom 3.3 (Priority of Creditors). For every $F \in \mathscr{F}$, for every $i \in N$, if $b_{i}(F)<L_{i}$, then it holds that $e_{i}(N, z, b(F))=0$.

Axiom 3.4 (Continuity). It holds that $b$ is continuous.

Axiom 3.5 (Impartiality). For every $F \in \mathscr{F}$, for every $i, j, k \in$ $N$, if $L_{i j}=L_{i k}$, then it holds that $b_{i j}(F)=b_{i k}(F)$.

Claims boundedness expresses that no agent needs to pay an amount in excess of its liabilities.

A bankruptcy rule satisfies limited liability if it leads to a payment matrix such that none of the agents ends up with negative equity.

A bankruptcy rule satisfies priority of creditors if the only circumstance under which an agent is allowed to default is when its equity is equal to zero. The axioms of limited liability and priority of creditors are closely related to the notions of limited liability and absolute priority, as introduced in Eisenberg and Noe (2001). In Eisenberg and Noe (2001), these notions are not formulated as properties of bankruptcy rules, but as requirements on the payment matrix, restricted to the case where each agent settles its liabilities proportionally.

To define continuity, we endow $\mathscr{F}$ with the standard topology, based on the discrete topology for $\mathcal{N}$ and the Euclidean topology for endowments and liabilities. Let $\left(F^{n}\right)_{n \in \mathbb{N}}=\left(N^{n}, z^{n}, L^{n}\right)_{n \in \mathbb{N}}$ be a sequence of financial networks of $\mathscr{F}$. Notice that this sequence converges to the financial network $\bar{F}=(\bar{N}, \bar{z}, \bar{L})$ of $\mathscr{F}$ if and only if there is $n^{\prime} \in \mathbb{N}$, such that for every $n \geq n^{\prime}$, it holds that $N^{n}=\bar{N}, \lim _{n \rightarrow \infty} z^{n}=\bar{z}$, and $\lim _{n \rightarrow \infty} L^{n}=\bar{L}$. Continuity is an attractive property of a bankruptcy rule because it implies that small changes in the financial network imply small changes in the resulting payment matrix.

Impartiality requires that two agents $j$ and $k$ with the same claim on agent $i$ should receive the same payment from $i$. Note that impartiality applies to payments made by an agent to its creditors, but not to payments received. Because one of the debtors could be bankrupt, such an axiom would make little sense. All bankruptcy rules for financial networks that are based on the well-known division rules for claims problems-like the proportional rule, the constrained equal awards rule, or the Talmud rule, to name a few-satisfy impartiality. In most real-life bankruptcy cases, the principle of impartiality is satisfied, which is in accordance with the EC Council Regulation on insolvency proceedings, requiring that creditors with the same standing should obtain the same proportion of their claims, and with American bankruptcy law, requiring that claimants of equal status should receive payments proportional to the value of their liabilities. In both legal systems, the repayment capacity of claimants is not taken into account.

Notwithstanding the dominance of impartiality in real-life bankruptcy cases, the principle of impartiality is applied somewhat differently in over-thecounter derivatives trades; see Duffie and Zhu (2011). First, claims are revised by doing one round of pairwise netting. Next, the proportional rule is applied to the revised claims. The revised claims have the property that for every pair of agents $i, j \in N$, it holds that $L_{i j}=0$ or $L_{j i}=0$. To capture this situation, we define the pairwise netting proportional rule.

Definition 3.6. The pairwise netting proportional rule pnp : $\mathscr{F} \rightarrow M$ is defined by

$$
\begin{array}{r}
p n p(N, z, L)=\min \left\{L, L^{\top}\right\}+p\left(N, z, L-\min \left\{L, L^{\top}\right\}\right), \\
(N, z, L) \in \mathscr{F} .
\end{array}
$$

Under the pairwise netting proportional rule, first, pairwise mutual payments are made, resulting in pairwise netting of the liabilities, and, next, the remaining liabilities are settled by using the proportional rule. The pairwise netting proportional rule is an example of a bankruptcy rule that is not based on a division rule for claims problems, because in this case, payments do not only depend on the asset value of an agent and its liabilities, but also on its claims toward other agents. We use the pairwise netting proportional rule to show the independence of our axioms in Appendix B. The following example shows that the pairwise netting proportional rule violates impartiality.

Example 3.7 (The Pairwise Netting Proportional Rule Does Not Satisfy Impartiality). Consider the financial network $(N, z, L) \in \mathscr{F}$ with three agents $N=\{1,2,3\}$ and endowments and liabilities as in the first two blocks of Table 2. Moreover, Table 2 presents the pairwise netting amounts $\min \left\{L, L^{\top}\right\}$, the payment matrix resulting from the proportional rule applied to the revised problem $P^{\prime}=p\left(N, z, L-\min \left\{L, L^{\top}\right\}\right)$, the payment matrix $\bar{P}=$ $p n p(N, z, L)$, asset values $a(\bar{P})$, and equities $e(\bar{P})$.

Notice that impartiality is not satisfied by the pairwise netting proportional rule, because agent 1 makes a payment of 10 units to agent 2 and of eight units to agent 3 , even though both agents hold the same claim against agent 1 . 
Table 2. The Endowments, the Liabilities, the Pairwise Netting Amounts $\min \left\{L, L^{\top}\right\}$, the Payment Matrix of the Revised Problem $P^{\prime}=p\left(N, z, L-\min \left\{L, L^{\top}\right\}\right)$, the Payment Matrix $\bar{P}=p n p(N, z, L)$, Asset Values $a(\bar{P})$, and Equities $e(\bar{P})$ in Example 3.7

\begin{tabular}{|c|c|c|c|c|c|c|c|c|c|c|c|c|c|c|c|c|c|}
\hline \multirow{2}{*}{$\frac{z}{12}$} & \multicolumn{3}{|c|}{$L$} & \multicolumn{3}{|c|}{$L^{\prime}$} & \multicolumn{3}{|c|}{$\min \left\{L, L^{\top}\right\}$} & \multicolumn{3}{|c|}{$P^{\prime}$} & \multicolumn{3}{|c|}{$\bar{P}$} & \multirow{2}{*}{$\frac{a(N, z, \bar{P})}{18}$} & \multirow{2}{*}{$\frac{e(N, z, \bar{P})}{0}$} \\
\hline & 0 & 12 & 12 & 0 & 6 & 12 & 0 & 6 & 0 & 0 & 4 & 8 & 0 & 10 & 8 & & \\
\hline 6 & 6 & 0 & 0 & 0 & 0 & 0 & 6 & 0 & 0 & 0 & 0 & 0 & 6 & 0 & 0 & 16 & 10 \\
\hline 6 & 0 & 0 & 0 & 0 & 0 & 0 & 0 & 0 & 0 & 0 & 0 & 0 & 0 & 0 & 0 & 14 & 14 \\
\hline
\end{tabular}

$L^{\prime}=L-\min \left\{L, L^{\top}\right\}$

$P^{\prime}=p\left(N, z, L-\min \left\{L, L^{\top}\right\}\right)$.

\section{Invariance to Mitosis and the Axiomatization}

For claims problems, nonmanipulability has been used by Angeles de Frutos (1999), Moreno-Ternero (2006), and Ju et al. (2007) to axiomatize the proportional rule. In that setting, nonmanipulability says that no group of agents can increase their total awards by merging their claims and that no single agent can increase its award by splitting its claim among dummy agents and itself. This axiom was introduced as strategyproofness by O'Neill (1982) for the class of simple claims problems, which are claims problems where no agent has a claim exceeding the estate. Strong nonmanipulability, introduced as the additivity of claims property by Curiel et al. (1987) for simple claims problems, says that if an agent splits its claim and appears as several different claimants, or a group of agents merge their claims and appear as a single claimant, nothing changes for the other agents involved in the problem.

A straightforward way to generalize strong nonmanipulability for claims problems to the setting of financial networks is to require that the split of an agent into multiple agents or the merger of a group of agents should not affect the payment matrix. We will show in Theorem 5.3 that nonmanipulability defined in such a way is too demanding in a network setting. The main problem is that a bankrupt agent can gain by allocating liabilities to a spin-off while keeping its endowments and claims. In real life, this kind of manipulation is illegal, because in winding up or in insolvency proceedings, the borrower is not allowed to do anything that would threaten directly or indirectly the payments to its lenders.

We therefore want to restrict splits and mergers to situations that are balanced in the sense that a spin-off that receives liabilities should also receive a corresponding amount of endowments and claims. The simplest way to achieve this is to restrict attention to manipulations involving identical agents, having the same endowments, claims, and liabilities. A split of an agent into identical agents is very common in real life. It occurs in case of a divorce when married in community of property. It turns out that this very weak requirement, called invariance to mitosis, together with the basic axioms, is sufficient to axiomatize the proportional rule.

Axiom 4.1 (Invariance to Mitosis). For every $F=(N, z, L) \in$ $\mathscr{F}$, for every $j \in N$, for every $K \subset \mathbb{N} \backslash N$, the payments in the financial network $F^{\prime}=\left(N^{\prime}, z^{\prime}, L^{\prime}\right) \in \mathscr{F}^{\prime}$, where

$$
\begin{aligned}
N^{\prime} & =N \cup K, & & \\
z_{k}^{\prime} & =z_{j} /(|K|+1), & & k \in\{j\} \cup K, \\
z_{i}^{\prime} & =z_{i,} & & i \in N \backslash\{j\}, \\
L_{k i}^{\prime} & =L_{j i} /(|K|+1), & & k \in\{j\} \cup K, i \in N \backslash\{j\}, \\
L_{i k}^{\prime} & =L_{i j} /(|K|+1), & & k \in\{j\} \cup K, i \in N \backslash\{j\}, \\
L_{k \ell}^{\prime} & =0, & & k, \ell \in\{j\} \cup K, \\
L_{h i}^{\prime} & =L_{h i}, & & h, i \in N \backslash\{j\},
\end{aligned}
$$

satisfy

$$
\begin{aligned}
\sum_{k \in\{j\} \cup K} b_{k i}\left(F^{\prime}\right)=b_{j i}(F), & i \in N \backslash\{j\}, \\
\sum_{k \in\{j\} \cup K} b_{i k}\left(F^{\prime}\right)=b_{i j}(F), & i \in N \backslash\{j\}, \\
b_{h i}\left(F^{\prime}\right)=b_{h i}(F), & h, i \in N \backslash\{j\} .
\end{aligned}
$$

We have formulated invariance to mitosis as the requirement that splitting an agent arbitrarily into multiple, but identical, agents should not affect the payments made to and received from the agents that are not involved in the split. Equivalently, we could have used the formulation that the merger of an arbitrary set of identical agents should not affect the payments made to and received from the agents that are not involved in the merger. Under a rule satisfying invariance to mitosis, the identical agents involved benefit neither from a split nor from a merger, giving two weak inequalities from which the first two equalities related to the payment matrix in Axiom 4.1 can be derived. The feature that also mutual payments 
between agents not involved in the split or merger do not change, the last equation in Axiom 4.1, makes this notion of nonmanipulability particularly robust, because it rules out the possibility that agents outside a split or merger would benefit from it and would be willing to make side payments to induce it. To sum up, invariance to mitosis requires that the split of an agent into multiple, but identical, agents or the merger of a group of agents that are identical should not affect the payment matrix.

We now turn to our axiomatization of the proportional rule.

Theorem 4.2. The proportional rule $p$ is the unique bankruptcy rule satisfying the axioms of claims boundedness, limited liability, priority of creditors, continuity, impartiality, and invariance to mitosis.

The proof of Theorem 4.2 can be found in Appendix A. We show the axioms to be independent in Appendix B.

Although invariance to mitosis applies to cases where an agent is split in identical agents, the proportional rule is easily verified to satisfy nonmanipulability in a much wider range of situations. It holds whenever all agents involved in a split remain solvent, which is not the case for bankruptcy rules for financial networks based on well-known division rules for claims problems like the constrained equal awards rule or the Talmud rule. For instance, under the constrained equal awards rule, agents benefit from splitting, even when they all remain solvent, because this increases the joint payments they receive from bankrupt agents. One can therefore conclude that nonmanipulability of the proportional rule applies exactly to those cases that are legally allowed, whereas because of Theorem 4.2, all other rules satisfying the basic axioms are manipulable, even when only splits in identical agents are considered. The proportional rule is therefore optimal when minimization of manipulation is the main concern. Other relevant concerns are how different bankruptcy rules affect the incentives to create profitable enterprises or influence welfare more generally. Such concerns are outside the framework that we consider here.

\section{Nonmanipulability}

In this section, we give a formal result on nonmanipulability being incompatible with the other basic axioms, even when one does not insist on continuity and impartiality.

Nonmanipulability requires the arbitrary split of an agent into multiple agents or the merger of a set of agents not to affect the payment matrix, formally defined as follows.
Axiom 5.1 (Nonmanipulability). For every $F=(N, z, L) \in$ $\mathscr{F}$, for every $j \in N$, for every $K \subset \mathbb{N} \backslash N$, the payments in every financial network $F^{\prime}=\left(N^{\prime}, z^{\prime}, L^{\prime}\right) \in \mathscr{F}$ such that

$$
\begin{aligned}
N^{\prime} & =N \cup K, \\
\sum_{k \in\{j\} \cup K} z_{k}^{\prime} & =z_{j,} \\
z_{i}^{\prime} & =z_{i}, \quad i \in N \backslash\{j\}, \\
\sum_{k \in\{j\} \cup K} L_{k i}^{\prime} & =L_{j i}, \quad i \in N \backslash\{j\}, \\
\sum_{k \in\{j\} \cup K} L_{i k}^{\prime} & =L_{i j}, \quad i \in N \backslash\{j\}, \\
L_{h i}^{\prime} & =L_{h i}, \quad h, i \in N \backslash\{j\},
\end{aligned}
$$

satisfy

$$
\begin{aligned}
\sum_{k \in\{j\} \cup K} b_{k i}\left(F^{\prime}\right)=b_{j i}(F), & i \in N \backslash\{j\}, \\
\sum_{k \in\{j\} \cup K} b_{i k}\left(F^{\prime}\right)=b_{i j}(F), & i \in N \backslash\{j\}, \\
b_{h i}\left(F^{\prime}\right)=b_{h i}(F), & h, i \in N \backslash\{j\} .
\end{aligned}
$$

We argue next that the requirement of nonmanipulability is too strong in financial networks. First, we show that it is not satisfied by the proportional rule.

Example 5.2 (The Proportional Rule Is Manipulable). We start from the financial network $F=(N, z, L) \in \mathscr{F}$ of Example 3.7 and calculate the payment matrix, asset values, and equities resulting from the proportional rule $p$ in Table 3 .

Consider a split of agent 1 into agents 1 and 4 , resulting in the financial network $F^{\prime}=\left(N^{\prime}, z^{\prime}, L^{\prime}\right)=$ $\left(N \cup\{4\}, z^{\prime}, L^{\prime}\right)$. In the split, agent 1 allocates half of its endowment and all of its liabilities to agent 4 , but none of its claims. The financial network $F^{\prime}$ is presented in Table 4 , as well as the payment matrix $P^{\prime}$ resulting from the proportional rule $p$.

Clearly, the proportional rule violates nonmanipulability, because $P_{12}=9 \neq 3=P_{12}^{\prime}+P_{42}^{\prime}$ and $P_{13}=9 \neq 3=P_{13}^{\prime}+P_{43}^{\prime}$. Agent 4 has no claims, and its liabilities exceed its

Table 3. The Endowments, Liabilities, Payment Matrix, Asset Values, and Equities Resulting from the Proportional Rule $p$ in Example 5.2 for the Financial Network $F=(N, z, L)$

\begin{tabular}{l|rrr|rrr|c|c}
\hline$z$ & $L$ & & & $P$ & & $a(N, z, P)$ & $e(N, z, P)$ \\
\hline 12 & 0 & 12 & 12 & 0 & 9 & 9 & 18 & 0 \\
6 & 6 & 0 & 0 & 6 & 0 & 0 & 15 & 9 \\
6 & 0 & 0 & 0 & 0 & 0 & 0 & 15 & 15 \\
\hline
\end{tabular}


Table 4. The Endowments, Liabilities, Payment Matrix, Asset Values, and Equities Resulting from the Proportional Rule $p$ in Example 5.2 for the Financial Network

$F^{\prime}=\left(N^{\prime}, z^{\prime}, L^{\prime}\right)$

\begin{tabular}{|c|c|c|c|c|c|c|c|c|c|c|}
\hline$z^{\prime}$ & \multicolumn{4}{|c|}{$L^{\prime}$} & \multicolumn{4}{|c|}{$P^{\prime}$} & $a\left(N^{\prime}, z^{\prime}, P^{\prime}\right)$ & $e\left(N^{\prime}, z^{\prime}, P^{\prime}\right)$ \\
\hline 6 & 0 & 0 & 0 & 0 & 0 & 0 & 0 & 0 & 12 & 12 \\
\hline 6 & 6 & 0 & 0 & 0 & 6 & 0 & 0 & 0 & 9 & 3 \\
\hline 6 & 0 & 0 & 0 & 0 & 0 & 0 & 0 & 0 & 9 & 9 \\
\hline 6 & 0 & 12 & 12 & 0 & 0 & 3 & 3 & 0 & 6 & 0 \\
\hline
\end{tabular}

endowment, so is sure to default on its liabilities. On the other hand, agent 1 has no liabilities, a positive endowment, and positive claims, so it will be solvent for sure. Agent 1 , who defaults in financial network $F$ and has $e_{1}(N, z, p(F))=0$, has split into a solvent agent 1 and a defaulting agent 4 in financial network $F^{\prime}$ with resulting equity $e_{1}\left(N^{\prime}, z^{\prime}, p\left(F^{\prime}\right)\right)=12$ and $e_{4}\left(N^{\prime}, z^{\prime}, p\left(F^{\prime}\right)\right)=0$. Obviously, if a bankrupt agent is allowed to allocate all its liabilities to a spin-off and keeps its endowment and claims to itself, it will end up with positive equity itself and a bankrupt spin-off.

We can generalize the findings of Example 5.2 to the following impossibility result.

Theorem 5.3. There is no bankruptcy rule satisfying claims boundedness, limited liability, priority of creditors, and nonmanipulability.

The proof of Theorem 5.3 can be found in Appendix A. The proof considers the financial network of Example 5.2 and shows that any bankruptcy rule with the stated properties requires agent 1 to make no payments and agent 4 to make a total of six units of payments in financial network $F^{\prime}$. Nonmanipulability can then be invoked to infer that agent 1 makes a total of six units of payments in financial network $F$. Agent 1 therefore ends up with positive equity in financial network $F$, which implies total payments equal to total liabilities of 24 units, leading to a contradiction.

\section{A Bankruptcy Rule That Violates Invariance to Mitosis}

In this section, we present a bankruptcy rule that satisfies all the axioms, except invariance to mitosis. ${ }^{3}$ In Appendix B, we present bankruptcy rules that violate exactly one of the other axioms. This demonstrates the independence of the axioms.

We construct a bankruptcy rule that is identical to the proportional rule for all financial networks with $N$ different from $\{1,2,3\}$. In case $N=\{1,2,3\}$, agents 1 and 2 still use the proportional rule to pay their liabilities, but agent 3 will pay agents 1 and 2 according to a division rule $d^{\prime}: \mathbb{R}_{+} \times \mathbb{R}_{+}^{2} \rightarrow \mathbb{R}_{+}^{2}$, where $d_{j}^{\prime}\left(A_{3},\left(L_{31}\right.\right.$, $\left.\left.L_{32}\right)\right)$ is the amount agent 3 pays to agent $j \in\{1,2\}$ if agent 3 has an asset value $A_{3} \in \mathbb{R}_{+}$and liabilities toward agents 1 and 2 equal to $\left(L_{31}, L_{32}\right) \in \mathbb{R}_{+}^{2}$. The division rule $d^{\prime}$ is defined as follows.

If $L_{31}+L_{32}<A_{3}$, then define $d_{1}^{\prime}\left(A_{3},\left(L_{31}, L_{32}\right)\right)=L_{31}$ and $d_{2}^{\prime}\left(A_{3},\left(L_{31}, L_{32}\right)\right)=L_{32}$. If $L_{31}+L_{32} \geq A_{3}$ and $L_{31}=0$, then define $d_{1}^{\prime}\left(A_{3},\left(L_{31}, L_{32}\right)\right)=0$ and $d_{2}^{\prime}\left(A_{3},\left(L_{31}, L_{32}\right)\right)=$ $A_{3}$. If $L_{31}+L_{32} \geq A_{3}$ and $L_{32}=0$, then define $d_{2}^{\prime}\left(A_{3},\left(L_{31}\right.\right.$, $\left.\left.L_{32}\right)\right)=0$ and $d_{1}^{\prime}\left(A_{3},\left(L_{31}, L_{32}\right)\right)=A_{3}$. Finally, in case $L_{31}+L_{32} \geq A_{3}$ and $\left(L_{31}, L_{32}\right) \gg 0$, let $d_{1}^{\prime}\left(A_{3},\left(L_{31}, L_{32}\right)\right) \geq$ 0 and $d_{2}^{\prime}\left(A_{3},\left(L_{31}, L_{32}\right)\right) \geq 0$ solve

$$
\begin{aligned}
d_{2}^{\prime}\left(A_{3},\left(L_{31}, L_{32}\right)\right) & =\frac{L_{32}}{\left(L_{31}^{\frac{L_{31}}{L_{32}}}\right)} d_{1}^{\prime}\left(A_{3},\left(L_{31}, L_{32}\right)\right)^{\frac{L_{31}}{L_{32}}} \\
A_{3} & =d_{1}^{\prime}\left(A_{3},\left(L_{31}, L_{32}\right)\right)+d_{2}^{\prime}\left(A_{3},\left(L_{31}, L_{32}\right)\right)
\end{aligned}
$$

Note that Equation (6.1) implies that $d_{2}^{\prime}\left(A_{3},\left(L_{31}, L_{32}\right)\right)$ is strictly increasing as a function of $d_{1}^{\prime}\left(A_{3},\left(L_{31}, L_{32}\right)\right)$, hence, there exists a unique solution to (6.1) and (6.2). For fixed $\left(L_{31}, L_{32}\right) \gg 0$, it holds that $d_{1}^{\prime}$ and $d_{2}^{\prime}$ are strictly increasing in $A_{3}$. Moreover, if $d_{1}^{\prime}\left(A_{3},\left(L_{31}, L_{32}\right)\right)=L_{31}$, then it holds that $d_{2}^{\prime}\left(A_{3},\left(L_{31}, L_{32}\right)\right)=L_{32}$ by $(6.1)$. We can use these facts to conclude that $d_{1}^{\prime}\left(A_{3},\left(L_{31}, L_{32}\right)\right) \leq L_{31}$ and $d_{2}^{\prime}\left(A_{3},\left(L_{31}, L_{32}\right)\right) \leq L_{32}$. It is easy to verify that the division rule $d^{\prime}$ is continuous.

The division rule $d^{\prime}$ is illustrated in Figure 1. Note that claimant 1 gets higher than proportional payments if $L_{31}>L_{32}$, proportional payments if $L_{31}=L_{32}$, and below proportional payments if $L_{31}<L_{32}$.

Let $b^{\prime}: \mathscr{F} \rightarrow M$ be the bankruptcy rule defined as follows.

If $N \neq\{1,2,3\}$, then $b^{\prime}(N, z, L)=p(N, z, L)$.

Figure 1. The Division Rule $d^{\prime}$ for $\left(L_{31}, L_{32}\right)=(20,40)$, $\left(L_{31}, L_{32}\right)=(40,40)$, and $\left(L_{31}, L_{32}\right)=(80,40)$ for All Levels of the Asset Value $A_{3}$

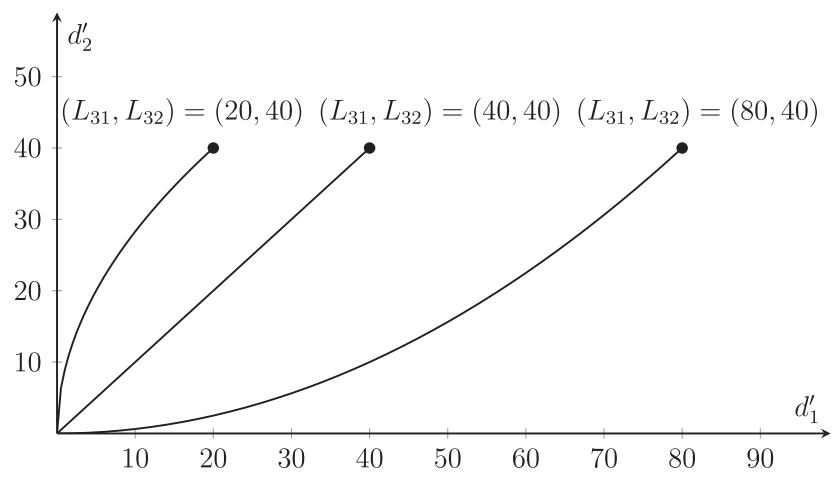


If $N=\{1,2,3\}$, then $b^{\prime}(N, z, L)=P$, where $P$ solves the following system of equations:

$$
\begin{aligned}
& P_{1 j}=\min \left\{\prod_{1 j}\left(z_{1}+\sum_{k \in N} P_{k 1}\right), L_{1 j}\right\}, \quad j \in N, \\
& P_{2 j}=\min \left\{\prod_{2 j}\left(z_{2}+\sum_{k \in N} P_{k 2}\right), L_{2 j}\right\}, \quad j \in N, \\
& P_{3 j}=d_{j}^{\prime}\left(z_{3}+\sum_{k \in N} P_{k 3},\left(L_{31}, L_{32}\right)\right), \quad j=1,2, \\
& P_{33}=0 .
\end{aligned}
$$

The uniqueness of the solution $P$ follows along the same lines as the proof for the proportional rule as given in theorem 2 of Eisenberg and Noe (2001). The bankruptcy rule $b^{\prime}$ coincides with the proportional rule, except when $N=\{1,2,3\}$. In this case, when agent 3 is bankrupt, it makes higher than proportional payments to agent 1 if $L_{31}>L_{32}$, proportional payments to agent 1 if $L_{31}=L_{32}$, and below proportional payments to agent 1 if $L_{31}<L_{32}$. It is easily verified that $b^{\prime}$ satisfies the axioms of claims boundedness, limited liability, priority of creditors, continuity, and impartiality.

The bankruptcy rule $b^{\prime}$ does not satisfy invariance to mitosis. For instance, let $F^{\prime}=\left(N^{\prime}, z^{\prime}, L^{\prime}\right)$ be a financial network, where $N^{\prime}=\{1,2,3,4\}$, agents 1,2 , and 4 are identical, and agent 3 is in fundamental default with positive liabilities to agents 1, 2, and 4 . Assume that there are no other positive liabilities. Because agents 1,2 , and 4 are identical, $L_{31}^{\prime}=L_{32}^{\prime}=$ $L_{34}^{\prime}$, and $b_{31}^{\prime}\left(F^{\prime}\right)=b_{32}^{\prime}\left(F^{\prime}\right)=b_{34}^{\prime}\left(F^{\prime}\right)=z_{3} / 3$. Now consider the financial network $F=(N, z, L)$ with $N=\{1,2,3\}$ that results after a merger between agents 1 and 4 . Because $L_{31}=L_{31}^{\prime}+L_{34}^{\prime}=2 L_{32}^{\prime}=2 L_{32}$, the use of the bankruptcy rule $b^{\prime}$ results in above proportional payments by agent 3 to agent 1 in financial network $F$, so $b_{31}^{\prime}(F)>$ $2 z_{3} / 3$, and invariance to mitosis is violated.

\section{Conclusion}

Many real-life bankruptcy problems are characterized by network aspects, meaning that the default of one agent can potentially snowball and lead to a chain of contagion defaults of other agents. As a consequence, the estates to be divided are endogenously determined, which makes the problem quite different from the typical case, as studied in the axiomatic bankruptcy literature. The most important bankruptcy rule from a practical perspective is the proportional rule. This makes an axiomatic analysis of the proportional bankruptcy rule in financial networks imperative.

An important aspect of actual bankruptcy problems is that entities can create spin-offs or merge. When such activities do not generate added value, they should not influence the payments to and from other entities and the payments between other entities. Such a property is known as nonmanipulability. An unrestricted ability to create spin-offs or form mergers clashes with nonmanipulability. Intuitively, an entity would have incentives to create a spin-off that contains all liabilities, while keeping all assets for itself. To avoid such unbalanced situations, we consider a much less demanding nonmanipulability property, called invariance to mitosis. In this case, it is required that the split of an entity into a number of identical ones or mergers of identical entities does not affect payments.

We show that invariance to mitosis leads to the proportional rule when complemented by the basic axioms of claims boundedness, limited liability, priority of creditors, continuity, and impartiality. We show all axioms to be independent. It is possible to drop the axiom of continuity when assuming that all liabilities are represented by rational numbers rather than reals. Although the very weak axiom of invariance to mitosis is sufficient to obtain the proportional rule, the proportional rule is robust to manipulations for a much wider range of situations. Whenever all agents involved in a split remain solvent, which corresponds to standard legal requirements, manipulation is not possible under the proportional rule.

We believe that the widespread use of the proportional rule in bankruptcy situations across countries and over time (see Engle (2012) for a historical account of the popularity of the proportional rule) is intimately related to the attractiveness and simplicity of the axioms characterizing it.

There are many possibilities for further research. The proportional rule and other bankruptcy rules in financial networks could be axiomatized by using different sets of axioms. It is far from straightforward to extend the results from claims problems to network problems by generalizing, for instance, no advantageous reallocation (Moulin 1987) or consistency (Young 1988). No advantageous reallocation would be attractive because it does not require the variable population context used in this paper. The problem is that reallocations can only be expected not to be advantageous if these reallocations are proportional, similar to our axiom of invariance to mitosis. But in a fixed population context, two agents with proportional characteristics may not exist, and the axiom loses its bite. Consistency requires that, in case one agent settles its affairs with the other agents and leaves the financial network, then an application of the rule to the reduced financial network leads to the same payments between the agents as before. The problem is that the reduced financial network may be outside our domain of financial networks, because 
agents may end up with negative initial endowments in the reduced financial network.

\section{Acknowledgments}

The authors thank three anonymous referees, Péter Biró, Francis Bloch, Dániel Deák, Gabrielle Demange, Thomas Demuynck, Matt Elliott, Sjur Didrik Flåm, Manuel Förster, Georg Kirchsteiger, Francois Maniquet, Jordi Massó, Francesco Nava, Miklós Pintér, Anthony Saunders, Roberto Serrano, Balázs Szentes, and participants of the 7th Annual Financial Market Liquidity Conference, the 11th Workshop on Economic Design and Institutions, the International Risk Management Conference 2017, the 13th European Meeting on Game Theory, and the 2019 Lisbon Meetings in Game Theory and Applications for helpful comments.

\section{Appendix A. Proofs}

The proof of Theorem 4.2 has two parts. In part (I), we show that the proportional rule satisfies claims boundedness, limited liability, priority of creditors, continuity, impartiality, and invariance to mitosis. In part (II), we prove that the proportional rule is the only rule satisfying these axioms. To prove this part, an important step is the insight that the axioms of impartiality and invariance to mitosis together imply that payments by agent $i$ to liabilities that are rational multiples of one another are proportional to these liabilities. This fact, together with the other axioms, except the axiom of continuity, is then used to show that the payment matrix satisfies Equation (2.1) in case all liabilities are rational numbers. The axiom of continuity is then invoked to extend this result to all financial networks.

Proof of Theorem 4.2, Part (I): The Proportional Rule $p$ Satisfies Claims Boundedness, Limited Liability, Priority of Creditors, Continuity, Impartiality, and Invariance to Mitosis. Consider the system of Equations (2.1).

Claims boundedness and impartiality follow immediately.

For limited liability, consider any creditor $i \in N$. If, for every $j \in N, L_{i j}=0$, then

$$
e_{i}(N, z, P)=z_{i}+\sum_{j \in N}\left(P_{j i}-P_{i j}\right)=z_{i}+\sum_{j \in N} P_{j i}>0 .
$$

Otherwise, we have that $\sum_{j \in N} \Pi_{i j}=1$, so

$e_{i}(N, z, P)=z_{i}+\sum_{j \in N}\left(P_{j i}-P_{i j}\right) \geq z_{i}+\sum_{j \in N}\left(P_{j i}-\Pi_{i j}\left(z_{i}+\sum_{k \in N} P_{k i}\right)\right)=0$,

where the last equality follows from $\sum_{j \in N} \prod_{i j}=1$.

Next, we show priority of creditors to hold. Take any financial network $F=(N, z, L) \in \mathscr{F}$ and any agent $i \in N$ such that $p_{i}(F)<L_{i}$. Then, we have that, for every $j \in N$,

$$
p_{i j}(F)=\Pi_{i j}\left(z_{i}+\sum_{k \in N} P_{k i}\right)=\prod_{i j} a_{i}(N, z, p(F)),
$$

so using $\sum_{j \in N} \prod_{i j}=1$, we get that

$$
\sum_{j \in N} p_{i j}(F)=\sum_{j \in N} \Pi_{i j} a_{i}(N, z, p(F))=a_{i}(N, z, p(F)),
$$

implying that $e_{i}(N, z, p(F))=0$.

Next, we show continuity to hold. Let $\left(F^{n}\right)_{n \in \mathbb{N}}=\left(N^{n}, z^{n}, L^{n}\right)_{n \in \mathbb{N}}$ be a sequence of financial networks in $\mathscr{F}$, which converges to the financial network $\bar{F}=(\bar{N}, \bar{z}, \bar{L})$ in $\mathscr{F}$. We have to show that the sequence of payment matrices $\left(p\left(F^{n}\right)\right)_{n \in \mathbb{N}}$ converges to the payment matrix $p(\bar{F})$. For $n \in \mathbb{N}$, we denote the relative liability matrix of $F^{n}$ by $\Pi^{n}$ and the payment matrix $p\left(F^{n}\right)$ by $P^{n}$. The relative liability matrix of $\bar{F}$ is denoted by $\bar{\Pi}$.

Without loss of generality, we can assume that, for every $n \in \mathbb{N}, N^{n}=\bar{N}$. Using the boundedness of the sequence $\left(P^{n}\right)_{n \in \mathbb{N}}$, we can assume without loss of generality that it has a limit $\bar{P} \in M(\bar{N})$. For every $n \in \mathbb{N}$, for every $i, j \in \bar{N}$, it holds by definition of $p$ that

$$
P_{i j}^{n}=\min \left\{\Pi_{i j}^{n}\left(z_{i}^{n}+\sum_{k \in \bar{N}} P_{k i}^{n}\right), L_{i j}^{n}\right\} .
$$

If $\bar{L}_{i j}=0$, then

$\bar{P}_{i j}=\lim _{n \rightarrow \infty} P_{i j}^{n} \leq \lim _{n \rightarrow \infty} L_{i j}^{n}=\bar{L}_{i j}=0=\min \left\{\bar{\Pi}_{i j}\left(\bar{z}_{i}+\sum_{k \in \bar{N}} \bar{P}_{k i}\right), \bar{L}_{i j}\right\}$.

If $\bar{L}_{i j}>0$, then

$$
\begin{aligned}
\bar{P}_{i j} & =\lim _{n \rightarrow \infty} P_{i j}^{n}=\lim _{n \rightarrow \infty} \min \left\{\Pi_{i j}^{n}\left(z_{i}^{n}+\sum_{k \in \bar{N}} P_{k i}^{n}\right), L_{i j}^{n}\right\} \\
& =\min \left\{\bar{\Pi}_{i j}\left(\bar{z}_{i}+\sum_{k \in \bar{N}} \bar{P}_{k i}\right), \bar{L}_{i j}\right\} .
\end{aligned}
$$

We have shown that $\bar{P}$ is a solution to the system of equations (2.1) corresponding to the financial network $\bar{F}$. Because this solution is unique by theorem 2 of Eisenberg and Noe (2001), it follows that $\bar{P}=p(\bar{F})$ as desired.

Finally, to show invariance to mitosis holds, take any financial network $F=(N, z, L) \in \mathscr{F}, j \in N$, and $K \subset \mathbb{N} \backslash N$. Consider the financial network $F^{\prime}=\left(N^{\prime}, z^{\prime}, L^{\prime}\right)$ with relative liability matrix $\Pi^{\prime}$ that results after the split of agent $j$ into identical agents in $\{j\} \cup K$.

We show that the payment matrix $P^{\prime} \in M\left(N^{\prime}\right)$ defined by

$$
\begin{array}{ll}
P_{k i}^{\prime}=p_{j i}(F) /(|K|+1), & k \in\{j\} \cup K, i \in N \backslash\{j\}, \\
P_{i k}^{\prime}=p_{i j}(F) /(|K|+1), & k \in\{j\} \cup K, i \in N \backslash\{j\}, \\
P_{k \ell}^{\prime}=0, & k, \ell \in\{j\} \cup K, \\
P_{h i}^{\prime}=p_{h i}(F), & h, i \in N \backslash\{j\},
\end{array}
$$

is a solution to the system of equations (2.1) for $F^{\prime}$.

We have three cases.

Case A.1. $L_{i h}^{\prime}=0, \quad i, h \in N^{\prime}$.

It follows immediately from the definition of $P^{\prime}$ in (A.1) that $P_{i h}^{\prime}=0$. 
Case A.2. $L_{i h}^{\prime}>0, \quad i \in N \backslash\{j\}, h \in N^{\prime}$.

It holds that

$a_{i}\left(N^{\prime}, z^{\prime}, P^{\prime}\right)=z_{i}^{\prime}+\sum_{\ell \in N^{\prime}} P_{\ell i}^{\prime}=z_{i}+\sum_{\ell \in N} p_{\ell i}(F)=a_{i}(N, z, p(F))$.

For every $h \in N \backslash\{j\}$, we have

$$
\begin{aligned}
P_{i h}^{\prime} & =p_{i h}(F)=\min \left\{\Pi_{i h} a_{i}(N, z, p(F)), L_{i h}\right\} \\
& =\min \left\{\Pi_{i h}^{\prime} a_{i}\left(N^{\prime}, z^{\prime}, P^{\prime}\right), L_{i h}^{\prime}\right\} .
\end{aligned}
$$

For every $h \in\{j\} \cup K$, we have

$$
\begin{aligned}
P_{i h}^{\prime} & =p_{i j}(F) /(|K|+1)=\min \left\{\Pi_{i j} a_{i}(N, z, p(F)), L_{i j}\right\} /(|K|+1) \\
& =\min \left\{\Pi_{i j} /(|K|+1) a_{i}(N, z, p(F)), L_{i j} /(|K|+1)\right\} \\
& =\min \left\{\Pi_{i h}^{\prime} a_{i}\left(N^{\prime}, z^{\prime}, P^{\prime}\right), L_{i h}^{\prime}\right\} .
\end{aligned}
$$

Case A.3. $L_{k h}^{\prime}>0, \quad k \in\{j\} \cup K, h \in N \backslash\{j\}$.

It holds that

$$
\begin{aligned}
a_{k}\left(N^{\prime}, z^{\prime}, P^{\prime}\right) & =z_{k}^{\prime}+\sum_{\ell \in N^{\prime}} P_{\ell k}^{\prime}=z_{j} /(|K|+1)+\sum_{\ell \in N} p_{\ell j}(F) /(|K|+1) \\
& =a_{j}(N, z, p(F)) /(|K|+1) .
\end{aligned}
$$

We have

$$
\begin{aligned}
P_{k h}^{\prime} & =p_{j h}(F) /(|K|+1)=\min \left\{\Pi_{j h} a_{j}(N, z, p(F)), L_{j h}\right\} /(|K|+1) \\
& =\min \left\{\Pi_{j h} a_{j}(N, z, p(F)) /(|K|+1), L_{j h} /(|K|+1)\right\} \\
& =\min \left\{\Pi_{k h}^{\prime} a_{k}\left(N^{\prime}, z^{\prime}, P^{\prime}\right), L_{k h}^{\prime}\right\}
\end{aligned}
$$

where the last equality follows from

$$
\Pi_{j h}=\frac{L_{j h}}{\sum_{\ell \in N} L_{j \ell}}=\frac{L_{j h} /(|K|+1)}{\sum_{\ell \in N} L_{j \ell} /(|K|+1)}=\frac{L_{k h}^{\prime}}{\sum_{\ell \in N^{\prime}} L_{k \ell}^{\prime}}=\Pi_{k h}^{\prime} .
$$

To show that the axioms of claims boundedness, limited liability, priority of creditors, continuity, impartiality, and invariance to mitosis imply the proportional rule, we will use the following lemma, where one liability of an agent is a positive rational multiple of another liability.

Lemma A.1. Let $F=(N, z, L) \in \mathscr{F}$ be a financial network, and let $i, j, k \in N$ and $q, r \in \mathbb{N}$ be such that $L_{i j}=(q / r) L_{i k}$. Let $b$ be $a$ bankruptcy rule satisfying impartiality and invariance to mitosis. Then, we have $b_{i j}(F)=(q / r) b_{i k}(F)$.

We first consider the case $r=1$. Let $F^{\prime}=\left(N^{\prime}, z^{\prime}, L^{\prime}\right) \in \mathscr{F}$ be the financial network where agent $j$ is split into $q$ identical agents $j$ and $\ell_{1}, \ldots, \ell_{q-1} \in \mathbb{N} \backslash N$, more precisely

$$
\begin{aligned}
N^{\prime} & =N \cup\left\{\ell_{1}, \ldots, \ell_{q-1}\right\}, & & \\
z_{j}^{\prime} & =z_{\ell_{1}}^{\prime}=\ldots=z_{\ell_{q-1}}^{\prime}=z_{j} / q, & & \\
z_{h}^{\prime} & =z_{h \prime}, & & h \in N \backslash\{j\}, \\
L_{j h}^{\prime} & =L_{\ell_{1} h}^{\prime}=\ldots=L_{\ell_{q-1} h}^{\prime}=L_{j h} / q, & & h \in N \backslash\{j\}, \\
L_{h j}^{\prime} & =L_{h \ell_{1}}^{\prime}=\ldots=L_{h \ell_{q-1}}^{\prime}=L_{h j} / q, & & h \in N \backslash\{j\}, \\
L_{h h^{\prime}}^{\prime} & =0, & & h, h^{\prime} \in\left\{j, \ell_{1}, \ldots, \ell_{q-1}\right\}, \\
L_{h h^{\prime}}^{\prime} & =L_{h h^{\prime}}, & & h, h^{\prime} \in N \backslash\{j\} .
\end{aligned}
$$

We have that

$$
b_{i j}(F)=b_{i j}\left(F^{\prime}\right)+b_{i \ell_{1}}\left(F^{\prime}\right)+\cdots+b_{i \ell_{q-1}}\left(F^{\prime}\right)=q b_{i k}\left(F^{\prime}\right)=q b_{i k}(F),
$$

where the first equality follows by invariance to mitosis, the second equality by impartiality, and the third equality again by invariance to mitosis.

We next consider the general case. Without loss of generality, we assume $q<r$. Let $F^{\prime}=\left(N^{\prime}, z^{\prime}, L^{\prime}\right) \in \mathscr{F}$ be the financial network where agent $k$ is split into $r$ identical agents $k$ and $\ell_{1}, \ldots, \ell_{r-1} \in \mathbb{N} \backslash N$, more precisely

$$
\begin{aligned}
N^{\prime} & =N \cup\left\{\ell_{1}, \ldots, \ell_{r-1}\right\}, & & \\
z_{k}^{\prime} & =z_{\ell_{1}}^{\prime}=\ldots=z_{\ell_{r-1}}^{\prime}=z_{k} / r, & & \\
z_{h}^{\prime} & =z_{h}, & & h \in N \backslash\{k\}, \\
L_{k h}^{\prime} & =L_{\ell_{1} h}^{\prime}=\ldots=L_{\ell_{r-1} h}^{\prime}=L_{k h} / r, & & h \in N \backslash\{k\}, \\
L_{h k}^{\prime} & =L_{h \ell_{1}}^{\prime}=\ldots=L_{h \ell_{r-1}}^{\prime}=L_{h k} / r, & & h \in N \backslash\{k\}, \\
L_{h h^{\prime}}^{\prime} & =0, & & i, j \in\left\{k, \ell_{1}, \ldots, \ell_{r-1}\right\}, \\
L_{h h^{\prime}}^{\prime} & =L_{h h^{\prime},} & & h, h^{\prime} \in N \backslash\{k\} .
\end{aligned}
$$

We have that

$$
\begin{aligned}
b_{i k}(F) & =b_{i k}\left(F^{\prime}\right)+b_{i \ell_{1}}\left(F^{\prime}\right)+\cdots+b_{i \ell_{r-1}}\left(F^{\prime}\right) \\
& =r b_{i k}\left(F^{\prime}\right)=\frac{r}{q} b_{i j}\left(F^{\prime}\right)=\frac{r}{q} b_{i j}(F),
\end{aligned}
$$

where the first equality follows by invariance to mitosis, the second equality from impartiality, the third equality from the first step in the proof because $L_{i j}^{\prime}=q L_{i k}^{\prime}$, and the fourth equality again by invariance to mitosis.

Proof of Theorem 4.2, Part II: If the Bankruptcy Rule $b$ Satisfies Claims Boundedness, Limited Liability, Priority of Creditors, Continuity, Impartiality, and Invariance to Mitosis, then $b=p$.

Let $F=(N, z, L) \in \mathscr{F}$ be a financial network, and let $b$ be a bankruptcy rule satisfying claims boundedness, limited liability, priority of creditors, continuity, impartiality, and invariance to mitosis. We show that $b(P)$ is a solution to the system of equations (2.1). We first assume all the liabilities to be rational numbers.

We consider two main cases.

Case A.4. $i, j \in N, L_{i j}=0$.

By claims boundedness, we have that $b_{i j}(F) \leq 0$, and from $b(F) \in M(N)$, we get that $b_{i j}(F)=0$.

Case A.5. $i, j \in N, L_{i j}>0$.

We have to show that

$$
b_{i j}(F)=\min \left\{\Pi_{i j}\left(z_{i}+\sum_{k \in N} b_{k i}(F), L_{i j}\right\} .\right.
$$

Case A.5(a). $z_{i}+\sum_{k \in N} b_{k i}(F)=a_{i}(N, z, b(F)) \geq \sum_{k \in N} L_{i k}$.

We have to show that $b_{i j}(F)=L_{i j}$. Suppose, on the contrary, that $b_{i j}(F) \neq L_{i j}$. Then, by claims boundedness, we have that

$$
b_{i j}(F)<L_{i j} \text {. }
$$


By priority of creditors, the assumption of Case A.5(a) claims boundedness, and (A.2), we get that

$$
\begin{aligned}
0=e_{i}(N, z, b(F))= & a_{i}(N, z, b(F))-\sum_{k \in N} b_{i k}(F) \\
& >\sum_{k \in N} L_{i k}-\sum_{k \in N} L_{i k}=0,
\end{aligned}
$$

a contradiction. Consequently, it holds that $b_{i j}(F)=L_{i j}$.

Case A.5(b). $z_{i}+\sum_{k \in N} b_{k i}(F)=a_{i}(N, z, b(F))<\sum_{k \in N} L_{i k}$.

We have to show that

$$
b_{i j}(F)=\prod_{i j} a_{i}(N, z, b(F)) .
$$

Because the liabilities are rational numbers, they are all rational multiples of one another, so we can use Lemma A.1 to conclude that there exists a real number $r_{i} \geq 0$, such that

$$
b_{i k}(F)=r_{i} L_{i k}, \quad k \in N .
$$

Thus, we have to show that

$$
r_{i}=\frac{a_{i}(N, z, b(F))}{\sum_{k \in N} L_{i k}} .
$$

By limited liability, we have that

$$
\sum_{k \in N} b_{i k}(F) \leq a_{i}(N, z, b(F)) .
$$

Suppose that

$$
\sum_{k \in N} b_{i k}(F)<a_{i}(N, z, b(F))
$$

Then, $e_{i}(N, z, b(F))>0$, and priority of creditors implies that $\sum_{k \in N} b_{i k}(F)=\sum_{k \in N} L_{i k}$, a contradiction to the assumption of Case A.5(b) and (A.8). Consequently, (A.7) holds with equality, and, by (A.5), we have that

$$
a_{i}(N, z, b(F))=\sum_{k \in N} b_{i k}(F)=\sum_{k \in N} r_{i} L_{i k}=r_{i} \sum_{k \in N} L_{i k},
$$

implying (A.6).

We have shown that $b(F)=p(F)$ when all liabilities in $F$ are rational numbers.

We now consider the case where the liabilities in $F$ are realvalued. Let $\left(F^{n}\right)_{n \in \mathbb{N}}$ be a sequence of financial networks, where all liabilities are rational numbers, converging to $F$. We have that

$$
b(F)=\lim _{n \rightarrow \infty} b\left(F^{n}\right)=\lim _{n \rightarrow \infty} p\left(F^{n}\right)=p(F),
$$

where the first equality follows from the axiom of continuity, the second follows because the liabilities in $F^{n}$ are all rational numbers, and the third because $p$ satisfies continuity by Theorem 4.2.

Proof of Theorem 5.3. Suppose $b$ is a bankruptcy rule satisfying claims boundedness, limited liability, priority of creditors, and non-manipulability. Let $F$ and $F^{\prime}$ be the financial networks as defined in Example 5.2. We define $P=$ $b(F)$ and $P^{\prime}=b\left(F^{\prime}\right)$.

By claims boundedness, it holds that

$$
P_{1}^{\prime}=(0,0,0,0),
$$

and

$$
e_{4}\left(N^{\prime}, z^{\prime}, P^{\prime}\right)=z_{4}^{\prime}+\sum_{i \in N^{\prime}} P_{i 4}^{\prime}-\sum_{i \in N^{\prime}} P_{4 i}^{\prime}=6-\sum_{i \in N^{\prime}} P_{4 i}^{\prime} .
$$

If $P_{4}^{\prime}=L_{4}$, then evidently $e_{4}\left(N^{\prime}, z^{\prime}, P^{\prime}\right)<0$, which would violate limited liability. It therefore holds that $P_{4}^{\prime} \neq L_{4}$ and by claims boundedness that $P_{4}^{\prime}<L_{4}$. Priority of creditors now implies that $\sum_{i \in N^{\prime}} P_{4 i}^{\prime}=6$. Claims boundedness implies $P_{41}^{\prime}=0$.

We now apply non-manipulability to derive that

$$
P_{12}=P_{12}^{\prime}+P_{42}^{\prime}, P_{13}=P_{13}^{\prime}+P_{43}^{\prime},
$$

so

$$
\begin{aligned}
\sum_{i \in N} P_{1 i} & =P_{11}+P_{12}+P_{13}=0+P_{12}^{\prime}+P_{42}^{\prime}+P_{13}^{\prime}+P_{43}^{\prime} \\
& =\sum_{i \in N} P_{1 i}^{\prime}+\sum_{i \in N} P_{4 i}^{\prime}=6,
\end{aligned}
$$

where the last equality comes from (A.10). It follows that

$$
e_{1}(N, z, P)=z_{1}+\sum_{i \in N} P_{i 1}-\sum_{i \in N} P_{1 i} \geq 12+0-6=6>0,
$$

so priority of creditors and claims boundedness yield $P_{1}=$ $L_{1}$ and

$$
\sum_{i \in N} P_{1 i}=\sum_{i \in N} L_{1 i}=24,
$$

a contradiction to (A.11). $\square$

\section{Appendix B. Independence of the Axioms}

In this section, we show the independence of the axioms claims boundedness, limited liability, priority of creditors, continuity, impartiality, and invariance to mitosis by providing six examples of bankruptcy rules satisfying all the axioms except one.

Example B.1 (All Except Claims Boundedness). Consider the following bankruptcy rule based on the proportional rule, but pretending that the liabilities are twice the actual liabilities. Let $b^{1}: \mathscr{F} \rightarrow M$ be defined by setting $b^{1}(N, z, L)=p(N$, $z, 2 L)$ for every $(N, z, L) \in \mathscr{F}$.

Then, $b^{1}$ obviously does not satisfy claims boundedness.

Recall that the proportional rule $p$ satisfies limited liability, priority of creditors, continuity, and impartiality by Theorem 4.2. It follows almost immediately that $b^{1}$ satisfies those properties. Because merging identical agents and then doubling the liability matrix leads to the same liability matrix as doubling the liability matrix first and then merging identical agents, invariance to mitosis for $b^{1}$ follows from invariance to mitosis for $p$.

Example B.2 (All Except Limited Liability). Consider the bankruptcy rule where all liabilities are paid. Let $b^{2}: \mathscr{F} \rightarrow M$ be defined by setting $b^{2}(N, z, L)=L$ for every $(N, z, L) \in \mathscr{F}$.

Then, $b^{2}$ clearly does not satisfy limited liability. Moreover, $b^{2}$ obviously satisfies claims boundedness, priority of creditors, continuity, impartiality, and invariance to mitosis.

Example B.3 (All Except Priority of Creditors). Consider the bankruptcy rule where nothing is paid. Let $b^{3}: \mathscr{F} \rightarrow \mathcal{M}$ be defined by setting $b^{3}(N, z, L)=0^{N \times N}$ for every $(N, z, L) \in \mathscr{F}$. 
Then, $b^{3}$ clearly does not satisfy priority of creditors. Moreover, $b^{3}$ obviously satisfies claims boundedness, limited liability, continuity, impartiality, and invariance to mitosis.

Example B.4 (All Except Impartiality). Consider the pairwise netting proportional rule pnp. We have shown in Example 3.7 that it does not satisfy impartiality.

Claims boundedness and continuity is obviously satisfied by pnp.

To check that $p n p$ satisfies limited liability, consider a financial network $F=(N, z, L) \in \mathscr{F}$ and any agent $i \in N$. Then,

$$
\begin{aligned}
e_{i}(N, z, p n p(F)) \\
=z_{i}+\sum_{j \in N} p n p_{j i}(F)-\sum_{j \in N} p n p_{i j}(F) \\
=z_{i}+\sum_{j \in N} \min \left\{L_{j i}, L_{i j}\right\}+\sum_{j \in N} p_{j i}\left(N, z, L-\min \left\{L, L^{\top}\right\}\right) \\
\quad-\sum_{j \in N} \min \left\{L_{i j}, L_{j i}\right\}-\sum_{j \in N} p_{i j}\left(N, z, L-\min \left\{L, L^{\top}\right\}\right) \\
=e_{i}\left(N, z, p\left(N, z, L-\min \left\{L, L^{\top}\right\}\right)\right) \geq 0,
\end{aligned}
$$

because the proportional rule $p$ satisfies limited liability. Thus, pnp satisfies limited liability.

To verify that $p n p$ satisfies priority of creditors, consider a financial network $F=(N, z, L) \in \mathscr{F}$ and any agent $i \in N$ such that $\operatorname{pnp}_{i}(F)<L_{i}$, implying that

$$
p_{i}\left(N, z, L-\min \left\{L, L^{\top}\right\}\right)<L_{i}-\min \left\{L_{i},\left(L^{\top}\right)_{i}\right\} .
$$

Because $p$ satisfies priority of creditors, (B.2) implies that

$$
e_{i}\left(N, z, p\left(n, z, L-\min \left\{L, L^{\top}\right\}\right)\right)=0 .
$$

Using the same argument as in (B.1), it follows that $e_{i}(N, z, p n p(F))=0$, thus $p n p$ satisfies priority of creditors.

To verify that $p n p$ satisfies invariance to mitosis, we define the bankruptcy rules $b^{4}: \mathscr{F}_{F} \rightarrow M$ and $b^{5}: \mathscr{F}_{F} \rightarrow M$ by setting, for $F=(N, z, L) \in \mathscr{F}, b^{4}(F)=\min \left\{L, L^{\top}\right\}$ and $b^{5}(F)=$ $p\left(N, z, L-\min \left\{L, L^{\top}\right\}\right)$. It holds that $p n p(F)=b^{4}(F)+b^{5}(F)$. We show that both $b^{4}(F)$ and $b^{5}(F)$ satisfy invariance to mitosis, from which it follows that $p n p$ satisfies invariance to mitosis.

It follows from the definition that $b^{4}$ satisfies invariance to mitosis, because merging identical agents will not change what they pay or receive in total by pairwise netting, and the liabilities within pairs of the other agents are not affected.

To show that $b^{5}$ satisfies invariance to mitosis, observe that merging identical agents first and executing pairwise netting next leads to the same liability matrix as pairwise netting first and merging identical agents next. Because $p$ satisfies invariance to mitosis, it follows that $b^{5}$ satisfies invariance to mitosis.

Example B.5 (All Except Continuity). Let $d^{\text {irr }}$ be the division rule for claims problems that gives priority to claims that belong to $\mathbb{R} \backslash \mathbb{Q}$ over claims that belong to $\mathbb{Q}$ and makes proportional payments within each of the two priority classes. So first all claimants with an irrational claim are paid in a proportional way. If after honoring their claims in full, there is still some estate left, then we turn to the claimants with rational claims and pay them in a proportional way. Let $b^{6}: \mathscr{F} \rightarrow \mathcal{M}$ be the bankruptcy rule defined as $b^{6}(N, z, L)=P$, where $P$ is the greatest solution to the following system of equations:

$$
P_{i j}=d_{j}^{\mathrm{irr}}\left(a_{i}(N, z, P), L_{i}\right), \quad i, j \in N .
$$

The fact that a greatest solution exists follows from an extension of arguments in Eisenberg and Noe (2001) and Csóka and Herings (2018) that are based on an application of Tarski's fixed point theorem. The bankruptcy rule $b^{6}$ obviously satisfies claims boundedness, limited liability, priority of creditors, and impartiality.

The division rule $d^{\text {irr }}$ is not continuous in the vector of claims. For instance, consider the case where one entry of a given vector of claims is a positive rational number and another entry is a positive irrational number. For a sequence of claims vectors with only rational entries that converges to the given vector of claims, it is only at the limit that the irrational claim gets priority. It now follows easily that the bankruptcy rule $b^{6}$ does not satisfy continuity.

Invariance to mitosis for $b^{6}$ is satisfied, because merging identical agents does not affect the priority classes of the claims and liabilities of the merged agent. Technically, the multiplication of a rational number by a natural number results in a rational number, and the multiplication of an irrational number by a natural number results in an irrational number. To verify that $b^{6}$ satisfies invariance to mitosis then follows the reasoning as for $p$.

Example B.6 (All Except Invariance to Mitosis). Consider the bankruptcy rule $b^{\prime}$ defined in Section 6, where we showed that $b^{\prime}$ does not satisfy invariance to mitosis. It is easy to check that $b^{\prime}$ satisfies claims boundedness, limited liability, priority of creditors, continuity, and impartiality.

\section{Endnotes}

${ }^{1}$ Council Regulation (EC) No. 1346/2000 of May 29, 2000 on insolvency proceedings: http://eur-lex.europa.eu/legal-content/EN/TXT/ HTML/?uri=CELEX:02000R1346-20140709\&qid=1471509284560.

${ }^{2}$ The idea to restrict manipulations to identical agents has also appeared in the literature on claims problems when axiomatizing the class of priority division rules; see the axiom of restricted additivity in Flores-Szwagrzak et al. (2019).

${ }^{3}$ We thank an anonymous reviewer for insisting to give this example a more prominent place in the discussion.

\section{References}

Acemoglu D, Ozdaglar A, Tahbaz-Salehi A (2015) Systemic risk and stability in financial networks. Amer. Econom. Rev. 105(2):564-608.

Angeles de Frutos M (1999) Coalitional manipulations in a bankruptcy problem. Rev. Econom. Design 4(3):255-272.

Bjørndal E, Jörnsten K (2010) Flow sharing and bankruptcy games. Internat. J. Game Theory 39(1-2):11-28.

Capponi A, Chen P-C, Yao DD (2016) Liability concentration and systemic losses in financial networks. Oper. Res. 64(5):1121-1134.

Chen C, Iyengar G, Moallemi CC (2013) An axiomatic approach to systemic risk. Management Sci. 59(6):1373-1388.

Cifuentes R, Ferrucci G, Shin HS (2005) Liquidity risk and contagion. J. Eur. Econom. Assoc. 3(2/3):556-566.

Csóka P, Herings PJJ (2018) Decentralized clearing in financial networks. Management Sci. 64(10):4681-4699. 
Curiel I, Maschler M, Tijs SH (1987) Bankruptcy games. Math. Methods Oper. Res. 31:A143-A159.

Demange G (2018) Contagion in financial networks: A threat index. Management Sci. 2018(2):955-970.

Duffie D, Zhu H (2011) Does a central clearing counterparty reduce counterparty risk? Rev. Asset Pricing Stud. 1(1):74-95.

Eisenberg L, Noe TH (2001) Systemic risk in financial systems. Management Sci. 47(2):236-249.

Elliott M, Golub B, Jackson MO (2014) Financial networks and contagion. Amer. Econom. Rev. 104(10):3115-3153.

Elsinger H, Lehar A, Summer M (2006) Risk assessment for banking systems. Management Sci. 52(9):1301-1314.

Engle E (2012) The history of the general principle of proportionality: An overview. Dartmouth Law J. 10(1):1-11.

Flores-Szwagrzak K, García-Segarra J, Ginés-Vilar M (2019) Priority and proportionality in bankruptcy. Social Choice Welfare 54:559-579.

Gai P, Kapadia S (2010) Contagion in financial networks. Proc. Roy. Soc. London A Math. Phys. Engrg. Sci. 466(2120):2401-2423.

Glasserman P, Young HP (2015) How likely is contagion in financial networks? J. Banking Finance 50:383-399.

Glasserman P, Young HP (2016) Contagion in financial networks. J. Econom. Lit. 54(3):779-831.

Groote Schaarsberg M, Reijnierse H, Borm P (2018) On solving mutual liability problems. Math. Methods Oper. Res. 87(3):1-27.

Ju B-G, Miyagawa E, Sakai T (2007) Non-manipulable division rules in claim problems and generalizations. J. Econom. Theory 132(1):1-26.

Kaminski MM (2000) 'Hydraulic' rationing. Math. Social Sci. 40(2): 131-155.
Moreno-Ternero JD (2006) Proportionality and non-manipulability in bankruptcy problems. Internat. Game Theory Rev. 8(1):127-139.

Moulin H (1987) Equal or proportional division of a surplus, and other methods. Internat. J. Game Theory 16(3):161-186.

Moulin H (2016) Entropy, desegregation, and proportional rationing. J. Econom. Theory 162:1-20.

Moulin H, Sethuraman J (2013) The bipartite rationing problem. Oper. Res. 61(5):1087-1100.

O'Neill B (1982) A problem of rights arbitration from the Talmud. Math. Social Sci. 2(4):345-371.

Rogers LCG, Veraart LAM (2013) Failure and rescue in an interbank network. Management Sci. 59(4):882-898.

Schuldenzucker S, Seuken S, Battiston S (2020) Default ambiguity: Credit default swaps create new systemic risks in financial networks. Management Sci. 66(5):1981-1998.

Shin HS (2008) Risk and liquidity in a system context. J. Financial Intermediation 17(3):315-329.

Tasnádi A (2002) On probabilistic rationing methods. Math. Social Sci. 44(2):211-221.

Thomson W (2013) Game-theoretic analysis of bankruptcy and taxation problems: Recent advances. Internat. Game Theory Rev. 15(3):1340018.

Thomson W (2015) Axiomatic and game-theoretic analysis of bankruptcy and taxation problems: An update. Math. Social Sci. 74:41-59.

Upper C (2011) Simulation methods to assess the danger of contagion in interbank markets. J. Financial Stability 7(3):111-125.

Young HP (1988) Distributive justice in taxation. J. Econom. Theory 44(2):321-335. 